\title{
Rethinking community participation in education post Covid-19
}

\author{
Radhika Iyengar ${ }^{1}$
}

Accepted: 23 December 2020 / Published online: 15 January 2021

(C) UNESCO IBE 2021

\begin{abstract}
Covid-19 has put education in a challenging place. With millions of children out of school, education needs to reinvent itself. During the pandemic, communities have used this opportunity to support children's education in various ways, including the launching of new online classes. This article takes the social capital theoretical model as its framework and applies it to help communities strengthen their education support systems. It also looks at models from the literature as best practices to operationalize social capital. The article highlights various models for community participation that could continue after the Covid-19 pandemic. It urges the school system to be flexible and incorporate community-driven parental engagement with project-based and experiential learning. These community-driven educational programs must be supported to provide much-needed place-based supplementary education opportunities to students.
\end{abstract}

Keywords Social capital · Community education · Parental involvement - Supplementary education $\cdot$ Covid-19

As of May 19, 2020, UNESCO (2020) noted that 58\% of the world's student population was out of school, affecting 1,009,085,427 students, with 135 countries facing closures, and hundreds of schools affected. Many children were not likely to return to school, and the ones who would were likely to lag in their learning levels. Before the pandemic, education systems followed a traditional path: children went to school and learned what was required for each grade level. However, during the lockdown, many different types of learning have been taking place. Children are learning empathy from their parents' collective action. They are learning life skills by staying at home and helping in household chores (Burke and Dempsey 2020). They are also learning digital skills by using TV, radio, smart/feature

Radhika Iyengar

iyengar@ei.columbia.edu

1 Center for Sustainable Development, Earth Institute, Columbia University, 61 Claremont Avenue \#1040, New York, NY 10027, USA 
phones, computers, and laptops (Livari et al. 2020). Parents have become co-facilitators in their children's learning process more than ever before. This nonlinear learning model has made children adapt their learning styles and learn from various sources.

For the post-Covid-19 scenario, I make the case that schools should build on the momentum and make schools more community resourced. Schools should focus on building a strong volunteer base that can help with students' learning. Many schools have parent-teacher associations (PTAs) or school-based management committees (SBMCs) that take on the task of school functioning (e.g., infrastructure developments and meals provision) through volunteer roles. However, the pandemic has shown how the community can be engaged in meaningful learning activities for children. All learning activities need not be school based; many activities can be done in communities with or without technology, as well as in homes.

In this article, I look at ways in which communities can be involved in children's education. I first discuss the social capital framework and use it as a theoretical underpinning for community engagement. The literature review operationalizes the social capital framework into eight models and shows various ways communities can be engaged in students' learning. I conclude by discussing lessons learned from the Covid-19 pandemic experience that can help educators rethink school curricula.

\section{Theoretical framework}

The theoretical framework used for this article is the vast literature on social capital. The use of informal community networks in education has been an underrepresented area of research. Informal networks form a big part of social capital (Sampson et al. 1999). This "neighborhood activism" (p. 207) translates into household-level networks within the family, and informal horizontal relationships that include neighbors talking to each other, church members interacting, and school parents discussing soccer and other such interactions (Schneider et al. 2000). Therefore, living in the same neighborhood provides incentives for people to be informally connected (Smrekar 1996). These informal connections, or social networks, are a source of cheap and useful bits of information (Schneider et al. 2000; Smrekar 1996). Parental exchanges without deep friendship can have an important effect on children's education (Schneider et al. 2000). Children in these types of communities share common values and have some support system that their parents can tap into (Adams 2006). In communities were more parents talk to each other, children benefit from added guidance and tend to have higher math scores (Adams 2006). In these ways, collective socialization has proven to be a powerful tool to shape children's education.

A vast literature explores the concept of social capital and ways to measure its impact on education. In a study based in Bogota, Knaul (1999) measured both family (numbers of hours spent with children, activities of engagement) and community social capital (gangs, drugs, measures of violence). The study reported that both family and community social capital had an impact on school dropout rates, controlling for household financial and human capital. In a similar study, Grootaert et al. (2002) investigated low school attendance in Burkina Faso and concluded that limited community participation in education was one of the main reasons for poor attendance. This study tapped into the concept of social capital through households, schools, and other non-formal settings and proposed the use of social capital to improve educational outcomes (attendance, in this case). 
Social capital is dependent on the cultural and contextual setting. The kinds of networks families establish have a long-lasting impact on their children's education. Research has shown the impact on children's completion rates in inner-city neighborhoods (Ainsworth 2002; Ensminger et al. 1996). This type of cultural capital also is labeled a "neighborhood effect" and acts a strong mediator for schooling-related indicators (Ainsworth 2002). Gugerty and Kremer (2002) attempted to understand if development aid for schools has helped to build social capital in Kenya. They conducted an experiment that compared three interventions: only textbooks were provided for 2 years, grants were given to the school committees as a part of a block grant, and the aid was provided through a local women's group. Their study revealed that it is difficult to build social capital from external interventions; rather, interventions should be organically present in communities.

Figure 1 shows the different areas where education can take place, and where the notion of social capital can be operationalized. Schools, communities, households, and nonformal spaces of education have social networks that are connected. These networks, both formal and informal, need to be tapped to make nonlinear education possible. Communities can support community library programs, expert-led professional seminars, open learning opportunities, and such community projects as gardening and services. This area also includes business owners, who can provide learn-play spaces. Educators in schools need to reflect on how to make education more holistic by incorporating classes on environmental education, disaster preparedness, health education, as well as mental well-being. PTAs need to help with students' learning. At the household level, parents can continue to support through life skills and activity-based learning. At the nonformal level, library programs, museums, zoos, and wildlife parks can continue to conduct online classes. These four quadrants form a seamless web of learning that can coexist, with the various areas complementing each other.

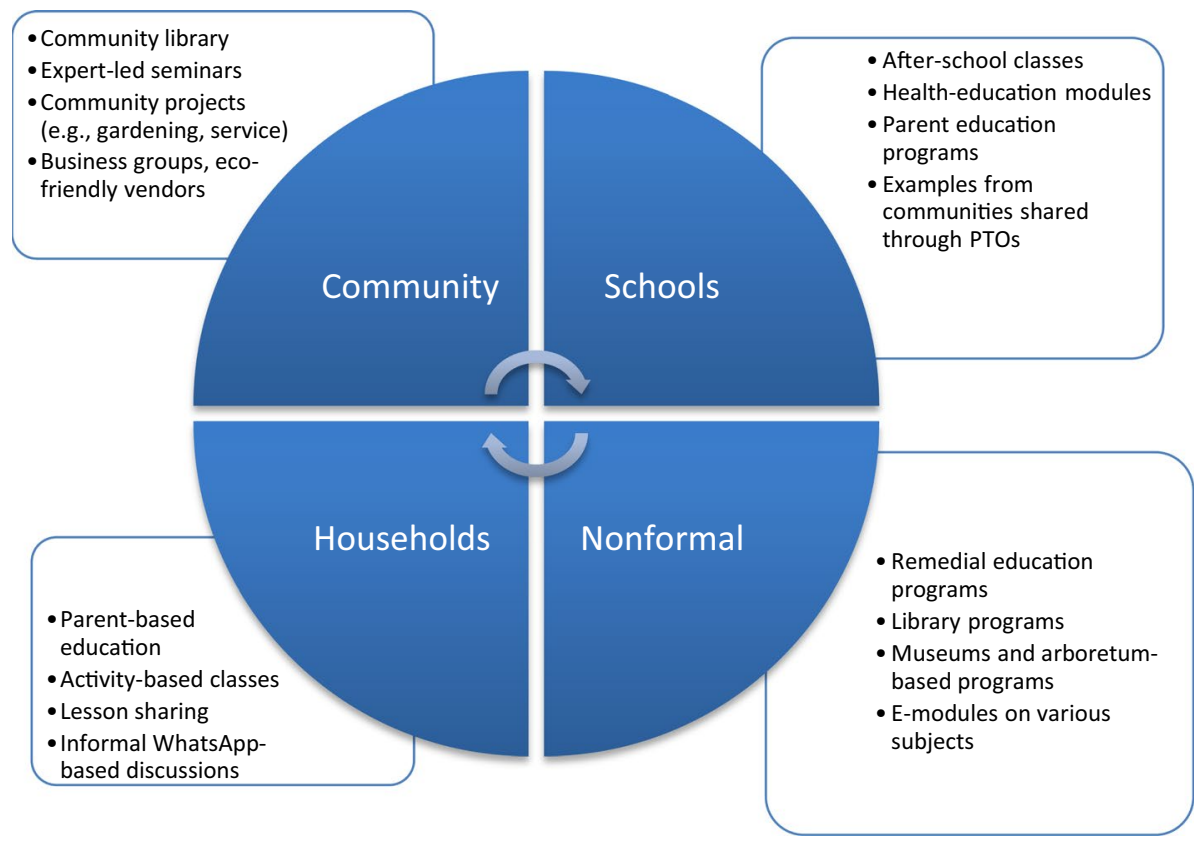

Figure 1 Operational framework 


\section{Operationalizing the definition of social capital}

In this section I discuss the existing literature on volunteers and community groups and their impact on education. Volunteers or parental groups are involved in many forms of education in communities. The responsibilities of volunteers and communities vary from country to country. For instance, community volunteers organized remedial education classes in a rural district in India. Volunteers complemented the school curriculum by introducing an alternative curriculum (School for Life Curriculum) in Ghana. They also campaigned for the use of indigenous languages in New Zealand. Multiple countries have used community-based libraries to foster the reading habits of all children. Volunteers in Honduras used a peer-tutoring model with youth residing in communities. In all these forms, the essential role of the community education volunteer is to support the existing formal school system and not to replace it. The community volunteer conducts community-based education-related activities that serve as an incentive to increase school enrollment or provide remediation to improve primary and secondary school completion.

Should educational activities spill over into communities? In most developing countries and especially in rural areas, parents are left out of the educational process. One reason for this exclusion is parents' lack of confidence because they are not educated themselves; other reasons include parents being busy with their daily chores during school time, and parents feeling their responsibility toward the education of their children ends when the children are enrolled in school. On the school organization side, the PTAs and SBMCs become ineffective because prior capacity enhancement of the parents is needed to make these administrative bodies functional. In such cases, the parents are not involved in their children's education, and even if they want to be, they do not know how. Parent engagement is critical to demanding quality education from the schools. One way of making children's education more accessible to their parents is to bridge the divide between the community and the school. Often, these education initiatives succeed because of intensive efforts to mobilize communities, resources, and local professionals.

Community-based initiatives are an effective means to operationalize national and sub-national government policies. They support, rather than duplicate, the schoolbased educational services offered by governments. However, thriving communitybased pilot programs are often highly dependent on local initiatives and commitment that are difficult to replicate on a large scale. It is also essential to keep in mind that community-based educational initiatives can take many forms. However, they are most often dependent on the community's needs and social capital. For instance, a community that has a large population of children out of school would need to focus on educational incentives (e.g., enrollment drives, school information sessions with parents) to bring those children to school. For communities with a large population of children lagging in literacy or numeracy skills, providing remedial education classes in the community, providing technical training assistance to government teachers on reading skills and numeracy, and community-based libraries would be appropriate interventions.

In this review, I provide examples of some such successful community-based volunteer models across the globe. I present a wide range of educational services that use the community volunteer model. The appropriate model should be selected based on the educational needs of the communities. 


\section{Model 1: Community-based education volunteers conduct reading remediation in India}

Policy initiatives involving communities are considered key in improving students' reading skills (UNESCO 2010). One such successful initiative is the remedial reading camps run by volunteer trainers to achieve impressive improvements in early reading in Uttar Pradesh, India. Such remediation activities help to mainstream students into formal schools with adequate learning preparation (Banerjee et al. 2007). In the post-Covid-19 world, learning gaps are expected to rise (Azevedo et al. 2020). Thus, community members getting together to conduct their own remedial camps could be one way of getting children ready for their grade level learning.

\section{Model 2: Addressing educational deprivation in northern Ghana through complementary education}

Many such community-based initiatives reach out to the marginalized student population. These programs are designed to accommodate the work schedules of students. They also help to make education more relevant to the students' lives. The goal of these short-term programs is to improve students' learning levels and mainstream them into the formal school system (Casely-Hayford et al. 2007; Hartwell 2006; Mfum-Mensah 2009). In the post-Covid-19 world, this model of understanding the needs of the students and making education relevant and contextual holds strong. The Covid-19 pandemic has left many students without adequate technology stranded (Livari et al. 2020) with no educational support. Reaching the hardest to reach in the post-Covid-19 world will require community members to develop support systems for schools.

\section{Model 3: Impact of educational campaigns on the community: New Zealand's Māori renaissance}

New Zealand's kōhanga reo movement has demonstrated the impact on the broader education system by an educational campaign. Educational campaigns, such as the revitalization of indigenous language, are beneficial for the large-scale implementation and adaptation of an educational agenda. These campaigns are mostly organized and planned by nongovernment organizations (NGOs) or community-based organizations with sizable volunteer support and community mobilization skills (Te Ko-hanga Reo National Trust 2009; New Zealand Ministry of Education 2008a, b, as cited in UNESCO 2010). As we rethink education systems in the post-Covid-19 world, sustaining the interest of community-based support for language to be inclusive should be a priority. Continued community support can be sustained if local languages are included as a medium of instruction in schools. 


\section{Model 4: Demanding accountability: A community-based approach in India}

Community-based initiatives also help to demand accountability from schools. In the case of Janaagraha, an NGO in India, the parents, along with the NGO members, kept track of schools' budgetary allocations and expenditures. This process made the schools more accountable in terms of the educational services they promise to deliver vis-a-vis their budgets (Iyengar 2010). This model suggests that NGOs and community members need to be included in school budget negotiations. In the post-Covid-19 scenario, making community members integral to the functioning of schools should be a priority. This will help communities be an integral part of school functioning, rather than on the periphery.

\section{Model 5: Community-based libraries}

Community-based libraries support the reading skills of children in the community. Many countries are implementing low-cost scalable models. Having libraries in the community, rather than in schools, helps to reach children not enrolled in school and to inculcate good reading habits among all children, as well as their parents. The pandemic has seen more parents circulating books (Iyengar 2020). After school closures, many community-based libraries started virtual classes for all ages. They also started to provide children's activity kits at the library. The library became the central place for many forms of education. This support system should continue, and libraries should become a community-based model for supporting children's education.

\section{Model 6: Community-based pre-primary centers}

Preschools are often neglected, both in implementation and national educational policies. In most developing countries, preschools are not part of compulsory education, and therefore most primary schools do not include preschools on their school premise. In such circumstances, government-run preschools are located outside the schools, or NGOs rent out small spaces in the communities to run preschool centers (Porta and Laguna 2007). In reimagining the post-Covid-19 world, educational spaces such as preschool centers run by the government or by cooperatives in the community will be needed to continue early childhood education. Such community spaces are important for an easy transition to formal school. Post pandemic, an enhanced version of these preschools will be needed to ensure that learning gaps are met.

\section{Model 7: Para-teachers: A volunteer model to support teachers in schools}

Para-teachers, or teacher helpers, are commonly used in countries that have teacher shortages. The role of para-teachers is primarily to assist full-time teachers in classroom teaching. Since classrooms in most developing-country settings have large class sizes, para-teachers help to manage the classrooms and provide assistance to children needing remedial education. In some cases, para-teachers are selected and recruited by community 
members, along with the school administration. This model helps to improve classroom teaching; however, the downside is that full-time teachers can become dependent on this temporary arrangement, or in some cases, give a lot of their teaching load to the parateachers (UNESCO 2005). This model could be further explored to hire youth from the community to teach in their local school, where they already have a rapport with the village children.

\section{Model 8: Volunteers provide psychosocial support}

Communities can provide targeted psychosocial support to students. Community members could provide recognition to the "best student in school" or the "model girl-child" in school. Getting recognition in the community encourages students, especially girls, to perform well in school. It also motivates parents to send their children to school (Brookings Institution 2011). Iyengar and Shin (2020) provided one such model that provided psychosocial support to students through an "eco-ambassadors" program during the pandemic. Daily check-in via Zoom calls to discuss environmental concerns also led to community building among like-minded people and developed a sense of community. Such informal conversations help to achieve educational goals-in this case, environmental educational goals - to build collaboration between students, and to create a sense of learning together. These informal communications will build psychosocial support and be vital for the post-Covid-19 world.

\section{Model 9: Peer tutoring and leadership development}

Peer tutoring has a positive impact on the learning of the two students involved. In most developing countries, teenagers who are recent graduates from secondary schools are engaged in teaching primary school students. These teenagers are gainfully employed while they pursue their higher degrees in education. The primary school students feel motivated to get extra support from someone in their community (Brookings Institution 2011). The pandemic has taught us about empathy, care for each other, global citizenship, and care for the planet, and these value-driven educational models will be much needed in the post-Covid-19 world. Model 9 shows a pathway to continue these value-driven education systems; peer tutoring not only improves teaching and learning skills but also develops important competency areas, such as psychosocial skills. Placement in leadership positions through volunteering to teach junior students is a useful model to enhance the learning levels of students during summers or through afterschool sessions.

\section{Discussions and conclusion}

These models demonstrate the different ways communities can be involved in their children's education in the post-Covid-19 world. Not all the activities mentioned in these models need to be school based. Parents and community members can be engaged in complementary activities, depending on their social capital. The models involve parents and community members in ways that help children's education. These activities have the potential to build local ecosystems and connect real-life issues to the school curriculum. 
Students get the required exposure to project-based learning opportunities that are connected to their lived realities. The objective of presenting these models was to understand that different pathways of social capital in neighborhoods can be operationalized to make the link between social capital and education stronger. In the post-Covid-19 world, it will become imperative for various forms of social capital to be used both in and outside school to ensure that children learn. These models capture existing pathways to act as a bridge between communities and schools.

These models provide different ways that communities can be engaged, including different ways of engagement between communities and schools. However, these models have not become the norm and standard practice. This paper urges the education community to rethink their own community models of engagement. Acknowledging that the community can be engaged in organic and nonlinear ways is a first step in this direction. Acknowledging that the community is integrated into the school system and can find ways to support students' learning is the need of the hour. The community members will help in making school education relatable and contextual to the local schools. The children will get more opportunities to apply their textbook-driven knowledge in their communities and neighborhood.

The structure for community involvement is already in place in many countries and schools. In many countries, it is mandatory for every school to have PTAs and SBMCs. However, these committees are not adequately used. Moreover, a big divide exists between the community and the school. The prevailing mindset is that education takes place in schools. Parental support is limited to their children. During the pandemic's time of social isolation, many educational networks were formed. Many volunteer-based online classes started, and parents took help from each other to fill in the school gap. Children used phones to chat and check in with their peers. Many different technological devices were used, including TV, radio, and laptops. Many kinds of software originally not used for educational purposes became educational communication software, including WhatsApp, Zoom, FaceTime, Facebook, and Skype. Others that were used widely included Khan Academy, YouTube, and Google classrooms. Many impromptu classes by community members were free for others, including free story sessions, yoga sessions, and piano classes.

Professional artists opened their homes to let technology be the medium for thousands to participate in their art. In the United States, universities such as Columbia and Rutgers had free webinars for kindergarten through grade-12 students on environmental sciences and sustainability practices. Other community-based professionals continued to teach using technology at a discounted rate. Rangers from national parks conducted online classes for free or for a small donation. Many students from across the United States joined these classes. Book authors conducted sessions on drawings and book reading.

This community-based model may have created more inequalities and is dependent on the type of social network a family has. However, it is important to note that community ownership of educational models, irrespective of the type of community, is an important factor in furthering and contextualizing education. Each community has its own social capital, and in the post-Covid-19 world, it will become increasing important to use it to improve learning gaps. Overtime, many of these inequalities will be addressed through technology reach, and we foresee many online educational degree programs emerging as a pathway forward.

Accessing these unconventional educational opportunities also depends on technology. Many communities may not have the technology that would be needed to serve as an equalizer. Going forward, here are some steps that ought to be taken. First, community-based 
assessments need to be carried out to assess the type of devices the majority of residents in the community have. Educational materials need customization to whatever device is most commonly used. The assessment should include the number of devices, the primary person owning the device, and the availability of the Internet. Second, a mapping of all educational opportunities, both free and paid, is required for parents to have full information in their own towns. Third, small-group classes on storytelling, book clubs, book exchanges, and exchanges of gardening skills should continue. Fourth, to make community members feel more connected to their neighborhood, community-based action or activism needs to be promoted. Fifth, more peer-to-peer learning and senior students teaching younger students should take place. Sixth, parents should be given an educational role to play that is not limited to conducting extracurricular activities at school or fundraising exercises. A more comprehensive network of parents needs to be established based on their interests. Seventh, cross-pollination of ideas across schools needs to be promoted. This network would make the social capital of students wider and not just limited to one school. Frequent opportunities need to be created district wide. Student-led online and offline events could be organized. Eight, mapping of community-wide (environmental, social, and other) needs can align students to address those needs. For example, if plastic is an issue, student groups can organize to do community-based activism and run campaigns. Nine, not everything needs to be organized beforehand; many activities can be planned last minute, and the school system and parents should be flexible to incorporate these opportunities. Ten, this is an excellent opportunity to build experiential and place-based learning into the curriculum. Problem-based activities connected to the lives of students can be integrated as projects into the school curriculum.

The closing of schools led to the opening of other educational avenues. This directs us to the question: what do children miss when schools open? This educational experience was very different from the traditional linear education model that connects the school to the child. The parents became more involved in their children's educational goals, and many resources were available to fill the school gap. Many networks were established, and many new connections were formed. This nonlinear educational model needs to have a place in the post-Covid-19 world. Parents, online resources, and technology-based communication media need to find a place in education. Education cannot go back to being only school based.

\section{References}

Adams, J. H. (2006). Community matters in China. In E. Hannum \& B. Fuller (Eds.), Children's lives and schooling across societies. Amsterdam: Elsevier.

Ainsworth, J. W. (2002). Why does it take a village? The mediation of neighboring effects on educational achievement. Social Forces, 81(1), 117-152.

Azevedo, J. P., Hasan, A., Goldemberg, D., Iqbal, A. S., \& Geven, K. (2020). Simulating the potential impacts of COVID-19 school closures on schooling and learning outcomes: A set of global estimates. Washington, DC: World Bank. https://doi.org/10.1596/1813-9450-9284.

Banerjee, A. V., Cole, S., Duflo, E., \& Linden, L. (2007). Remedying education: Evidence from two randomized experiments in India. The Quarterly Journal of Economics, 122(3), 1235-1264.

Brookings Institution (2011). A global compact on learning: Taking action on education in developing countries. Washington, DC: Brookings Institution. https:/www.brookings.edu/events/a-globa 1-compact-on-learning-taking-action-on-education-in-developing-countries/.

Burke, J., \& Dempsey, M. (2020). Covid-19 practice in primary schools in Ireland report. Maynooth: Maynooth University. https://doi.org/10.13140/RG.2.2.14091.03369. 
Casely-Hayford, L., Ghartey, A. B., \& SfL Internal Impact Assessment Team (2007). The leap to literacy and life change in Northern Ghana: An impact assessment of School for Life (SfL). Tamale: School for Life.

Ensminger, M. E., Lamkin, R. P., \& Jacobson, N. (1996). School leaving: A longitudinal perspective including neighborhood effects. Child Development, 67(5), 2400-2416.

Grootaert, C., Oh, G.-T., \& Swamy, A. (2002). Social capital, education and credit markets: Empirical evidence from Burkina Faso. In J. Isham, T. Kelly, \& S. Ramaswamy (Eds.), Social capital and economic development: Well-being in developing countries (pp. 85-98). Cheltenham: Edward Elgar Publishers.

Gugerty, M. K., \& Kremer, M. (2002). The impact of development assistance on social capital: Evidence from Kenya. In C. B. Grootaert \& T. van Bastelaer (Eds.), The role of social capital in development: An empirical assessment (pp. 213-233). Cambridge: Cambridge University Press.

Hartwell, A. (2006). Meeting EFA: Ghana School for Life. EQUIP2 working paper. Washington, DC: USAID/Academy for Educational Development.

Iyengar, R. (2010). Different implementation approaches to a common goal: Education for all in the Indian context. Society for International Education Journal, 7, 1-7.

Iyengar, R. (2020). Education as the path to a sustainable recovery from COVID-19. Prospects, 49, 77-80. https://doi.org/10.1007/s11125-020-09488-9.

Iyengar, R., \& Shin, H. (2020). Community-based programs to tackle environmental education and COVID-19: A case study from Millburn, New Jersey. Prospects. https://doi.org/10.1007/s1112 5-020-09467-0.

Kaul, R. (2001). Accessing primary education: Going beyond the classroom. Economic and Political Weekly, 36(2), 155-162.

Livari, N., Sharma, S., \& Venta-Olkkonen, L. (2020). Digital transformation of everyday life: How COVID-19 pandemic transformed the basic education of the young generation and why information management research should care? International Journal of Information Management. https://doi. org/10.1016/j.ijinfomgt.2020.102183.

Mfum-Mensah, O. (2009). An exploratory study of the curriculum development process of a complementary education program for marginalized communities in Northern Ghana. Curriculum Inquiry, 39(2), 343-367.

New Zealand Ministry of Education (2008a). Early childhood education enrolments. Wellington: New Zealand Ministry of Education. www.educationcounts.govt.nz/_data/assets/excel_doc/0008/34865 /ECE_Licensed_Enrolments_2008_tables.xls.

New Zealand Ministry of Education (2008b). MÇori medium education July 2008 and MÇori medium time-series tables. Wellington: Ministry of Education. www.educationcounts.govt.nz/_data/assets/ excel_doc/0008/34865/ECE_Licensed_Enrolments_2008_tables.xls.

Porta, E., \& Laguna, J. R. (2007). Nicaragua. Country case study. Country profile prepared for the Education for All Global Monitoring Report 2008. Paris: UNESCO.

Sampson, R. J., Morenoff, J. D., \& Earls, F. (1999). Beyond social capital: Spatial dynamics of collective efficacy for children. American Sociological Review, 64, 633-660.

Schneider, M., Teske, P., \& Marschall, M. (2000). Choosing schools: Consumer choice and the quality of American schools. Princeton: Princeton University Press.

Smrekar, C. (1996). The impact of school choice and community in the interest of families and schools. New York, NY: State University of New York Press.

Te Ko-hanga Reo National Trust (2009). Te Ko-hanga Reo. http://www.kohanga.ac.nz.

UNESCO (2004). Gender and education for all: The leap to quality. EFA Global Monitoring Report. Paris: UNESCO. https://unesdoc.unesco.org/ark:/48223/pf0000132513.

UNESCO (2005). Education for all: The quality imperative. EFA Global Monitoring Report. Paris: UNESCO. https://unesdoc.unesco.org/ark:/48223/pf0000137333.

UNESCO (2008). Education for all by 2015: Will we make it? EFA Global Monitoring Report. Paris: UNESCO. https://unesdoc.unesco.org/ark:/48223/pf0000154743.

UNESCO (2010). Reaching the marginalized. EFA Global Monitoring Report. Paris: UNESCO. https:// unesdoc.unesco.org/ark:/48223/pf0000186606.

UNESCO (2020). Education: From disruption to recovery. Paris: UNESCO. https://en.unesco.org/covid 19/educationresponse.

Publisher's Note Springer Nature remains neutral with regard to jurisdictional claims in published maps and institutional affiliations. 
Radhika Iyengar has been working in the areas of sustainable development and environmental education at the Center for Sustainable Development (Earth Institute, Columbia University) since 2011. She has been working with governments and NGOs all over the world, advising on designing education and environmental education programs. In 2020, she received the Earth Frontiers grant on community-based education on fluoride testing. Currently she is the Chair of Environmental and Sustainability Education Special Interest Group at the Comparative and International Education Society (CIES). 